\title{
Selection of trees for rubbing by red and roe deer in forest plantations
}

\author{
Jaime A. Ramos ${ }^{\mathrm{a}, 1}$, Miguel N. Bugalho ${ }^{\mathrm{b}, 1, *}$, Paulo Cortez $^{\mathrm{c}}$, Glenn R. Iason ${ }^{\mathrm{d}}$ \\ a Department of Zoology, University of Coimbra, P3004-517 Coimbra, Portugal \\ ${ }^{\mathrm{b}}$ Center for Applied Ecology "Baeta Neves", Instituto Superior de Agronomia, \\ Tapada da Ajuda, Lisboa 1349-017, Portugal \\ ${ }^{\mathrm{c}}$ Escola Superior Agrária, Polytechnic Institute of Bragança, 5301-854 Bragança, Portugal \\ ${ }^{\mathrm{d}}$ The Macaulay Institute, Craigiebuckler, Aberdeen AB15 $8 Q H, U K$
}

Received 7 January 2005; received in revised form 31 May 2005; accepted 3 October 2005

\begin{abstract}
Antler rubbing is a form of behaviour by which deer may damage and ultimately induce mortality of trees. Understanding factors affecting selection of trees for rubbing may contribute to mitigation of negative effects of such behaviour in plantations or woodlands. We analysed characteristics of trees rubbed by red and roe deer along transects established in plantations of Pinus pinaster (Aiton), Pseudotsuga menziesii (Mirbel) Franco, Betula alba L. and Quercus robur L. in Northeast Portugal. Transects were walked during five sampling periods covering mating seasons of red and roe deer. Red deer preferentially rubbed trees adjacent to the edge of plantations and large clearings whilst roe deer selected those inside plantations within small clearings. There was seasonal segregation in the number of trees rubbed by each deer species with red deer rubbing trees mainly between September and February and roe deer mainly between December and June. Both red and roe deer selected trees with smaller diameter than those of available trees although trees selected by red deer had larger diameters than those selected by roe deer. Roe, but not red deer, tended to avoid trees protected by shrubs. Overall, the selection of trees for rubbing was site-dependent suggesting that generalizations across sites should be made with caution. Mitigating measures, such as deer control, tree protection or provision of alternative rubbing posts should target stands of particular tree species, location of trees in relation to stand clearings and tree size classes.
\end{abstract}

(C) 2005 Elsevier B.V. All rights reserved.

Keywords: Capreolus capreolus; Cervus elaphus; Fraying; Portugal; Rubbing

\section{Introduction}

Deer populations have been expanding both in Europe and North America (Rooney, 2001; Fuller and Gill, 2001) partly due to land use changes such as agricultural abandonment and increase of forested areas (Putman and Moore, 1998; Fuller and Gill, 2001). The effects of deer browsing and grazing on the establishment of trees and vegetation have been widely reported for temperate forest systems (Gill and Beardall, 2001; Virtanen et al., 2002; Harmer, 2002; Kirby, 2001) whereas other forms of interaction with trees, such as antler rubbing behaviour, have been less intensively investigated.

Deer commonly rub their antlers against trees causing damage (e.g. decline in wood quality) that may lead to significant

\footnotetext{
* Corresponding author.

${ }^{1}$ These authors contributed equally to this work.
}

economic losses in forest plantations (Nielsen et al., 1982; Gill, 1992). Rubbing is conducted by male deer and may serve both comfort (cleaning dead velvet from antlers) and territoriality (marking behaviour) functions (Geist, 1998). The relative importance and significance of these functions, both for deer and trees, is likely to vary with the ecology, pattern of habitat use, degree of territoriality and peak of mating activity of each deer species.

Selection of trees for rubbing has been examined in whitetailed deer Odocoileus virginianus (Boddaert) (Kile and Marchinton, 1977; Miller et al., 1987; Oeheler et al., 1995), fallow deer Dama dama L. (Massei and Bowyer, 1999), moose Alces alces L. (Bowyer et al., 1994) and roe deer Capreolus capreolus L. (Johansson and Liberg, 2000) and was found to be dependent on tree species, aromatic properties, trunk diameter or physical accessibility of trees (Massei and Bowyer, 1999).

It has been suggested that rubbing may simply produce a visible sign on a tree demarcating a territory or the presence of a 
male in the area, or be associated with scent marking (Bowyer et al., 1994; Johansson et al., 1995; Carranza and MateosQueseda, 2001). While visible signs may be associated with visual communication through "sign-post signalling" (Benner and Bowyer, 1988), scent marking is usually associated with establishment of social hierarchies among males (Ralls, 1971; Geist, 1998). Rubs may thus serve as visual and olfactory marks related to male dominance. Placing these signs on trees readily located by conspecifics may be advantageous (Benner and Bowyer, 1988). As the importance and function of rubbing may vary among deer species, effects on trees are also likely to vary accordingly. Although different deer species frequently coexist in the same areas, the few published studies have focused on single deer species. Moreover, in spite of the implications of rubbing to trees and plantations or woodlands, in most reports this topic is incidental to other aspects of the studies in question (Johansson and Liberg, 2000) and few quantify the effects of deer rubbing behaviour (Putman and Moore, 1998).

Red and roe deer populations are expanding across Europe (Gill, 1992; Putman and Moore, 1998) and the effects these species have on trees are also likely to increase. In Northeast Portugal, for instance, rubbing by red Cervus elaphus L. and roe deer is an important source of damage to trees and economic losses in forest plantations and agricultural orchards (J.L. Rosa, unpublished data). Understanding the factors affecting tree selection as well as spatial and temporal variation of rubbing caused by coexisting populations of red and roe deer is important both biologically, for contributing to mitigation measures, and economically.

In the present study we investigated factors associated with rubbing behaviour of red and roe deer, two sympatric deer species with contrasting seasonality, in NE Portugal. We examined how tree species, trunk diameter and physical accessibility varied among trees rubbed by red and roe deer in single-species plantations of Pinus pinaster, Pseudotsuga menziesii, Betula alba and Quercus robur. Temporal patterns of antler growth are markedly different between red and roe deer. In red deer, antler growth starts in early spring (March) whilst in roe deer it occurs in winter (November-December) (Sempéré et al., 1998). As a consequence, main periods of rubbing activity associated with the cleaning of the antler velvet, should be temporally segregated between the two species. In particular we aimed to: (1) examine temporal and spatial variation in the number of trees rubbed by red and roe deer, (2) describe the physical characteristics of trees selected by red and roe deer for rubbing and (3) compare characteristics of trees rubbed by red or roe deer with those of available and nearest unrubbed trees.

\section{Methods}

\subsection{Study area}

The study was conducted in Montesinho Natural Park, Northeast Portugal $\left(6^{\circ} 49^{\prime} 07^{\prime \prime} \mathrm{W}, 41^{\circ} 53^{\prime} 05^{\prime \prime} \mathrm{N}\right)$ an area where distributions of red and roe deer populations overlap. Populations of red and roe deer have been recently expanding in this protected area (Paiva, 2004) partially due to favourable habitat changes and limited culling policies adopted within the park. Estimated densities of red and roe deer in the area are approximately of $0.03-0.04$ and $0.01-0.02$ individuals/ha, respectively (Paiva, 2004). Deer rubbing of adult trees is thought to be an important source of economic losses in the area. Damage to trees, in plantations and agricultural crops, has been increasingly reported by farmers and foresters inhabiting the area.

Plantations of conifers Pinus pinaster, and P. menziesii and of deciduous species $B$. alba and $Q$. robur are common in the study area. Physical characteristics of trees (see below) were examined in four unfenced plantations of Pinus pinaster, two of P. menziesii, one of $B$. alba and a small plantation of $Q$. robur. All plantations had approximately uniform density of trees, although natural thinning, natural regeneration and lack of management had created clearings of different sizes, with a shrub understorey composed mainly of plants of the genus Erica spp., Ulex spp., Cistus spp. and Cytisus spp. The plantations selected for the study were used both by red and roe deer.

\subsection{Field methods}

As most plantations had an approximately rectangular shape, we established two transects that traversed each plantation: one along the greatest length and another perpendicular to the first transect, and bisecting it at its approximate mid point. Transect length varied between 50 and $600 \mathrm{~m}$. Points were then located systematically every $30 \mathrm{~m}$ along transects and the tree located nearest to each of these points (hereafter designated as "available trees") were tagged. Additionally, all trees found rubbed (hereafter called "rubbed trees") by deer within a $10 \mathrm{~m}$ wide band along the transect ( $5 \mathrm{~m}$ to each side of transect) were recorded and tagged. We considered a tree as having been rubbed when a fraction of the bark had been clearly scrapped away by the use of antlers. Rub appearance differ greatly between deer species and can be easily distinguished by an experienced observer. Roe deer rubs are smaller in length and width and located much closer to ground than red deer rubs. For instance, in our study area, distance between ground and the middle of the rub (mean \pm S.E. $)$ was $1.10 \pm 0.03 \mathrm{~m}$ for red deer $(n=94)$ and $0.53 \pm 0.03 \mathrm{~m}$ for roe deer $(n=42)$. Also, in another study conducted in an area in Southern Portugal, where red but not roe deer occurred (Bugalho et al., unpublished), distance between ground and the middle of the rub was $1.12 \pm 0.45 \mathrm{~m}(n=45)$. It was thus very unlikely that a rub could be misclassified between deer species. For each of all rubbed and tagged trees the nearest unrubbed tree (hereafter called "unrubbed trees") was located. We sampled 160, 46, 46 and 20 trees of Pinus pinaster, $P$. menziensii, B. alba and $Q$. robur, respectively. These sample sizes included "rubbed", "unrubbed" and "available" trees.

In order to examine temporal variation in the number of newly rubbed trees, transects in five plantations (three of Pinus pinaster, one of $P$. menziensii and one of $B$. alba) were walked during five sampling periods covering mating seasons of both 
red and roe deer: (1) late September and (2) mid-November to late December of 2000 and (3) mid-January to mid-February, (4) mid-April to mid-May, and (5) late July 2001. Trees newly rubbed by each deer species along the two transects established in each plantation were tagged and counted during each sampling period. Transects in the three remaining plantations were walked only twice (mid-November to late December and mid-April to mid-May) to increase the sample size of rubbed and nearest unrubbed trees.

Preliminary surveys showed an apparently higher number of trees rubbed at the edge of plantations. Thus we also tabulated rubbed trees according to distance from the edge of the plantation using the following classes of distance: 0-10, 11-20, 21-30 and $>30 \mathrm{~m}$. Whilst "available trees" should represent total tree variability in the plantation (i.e. at a larger scale of selection) "rubbed" and "nearest unrubbed" trees should represent local variability (local scale of selection) within the plantation.

Variables reflecting tree size and accessibility (Table 1) were recorded for the populations of "available", "rubbed" and "unrubbed" trees. Characteristics of rubbed and unrubbed trees were recorded during each sampling period, but those of available trees were recorded only in September, as we did not expected the measured characteristics of available trees in a plantation to show relevant differences between September and the following May.

\subsection{Statistical analyses}

We used G-likelihood ratio tests (Sokal and Rohlf, 1995) to compare main rubbing periods of red and roe deer and to test the null hypotheses of no difference in the number of trees marked by each deer species in relation to the distance from the edge of the plantations (0-10, 11-20, 21-30 and >30 m). Fifteen trees rubbed by red deer located at more than $30 \mathrm{~m}$ from the edge of the plantation were discarded from the analysis as they were located in a large clearing. G-likelihood ratio tests were also used for comparing the proportions of trees of each species rubbed by red and roe deer.

We compared traits (diameter, distance to nearest tree, shrub cover) of available trees with trees rubbed by red or roe deer, traits of trees rubbed by red or roe deer with traits of nearest unrubbed trees and traits of trees rubbed by red with traits of those rubbed by roe deer using residual maximum likelihood (REML) analysis (Genstat 6th for Windows, 2002) which permits an unbalanced design and unequal numbers of replicates in each treatment (see below). Specific post-hoc comparisons between categories of explanatory variables

Table 1

Variables recorded for available, rubbed and nearest unrubbed trees

\begin{tabular}{ll}
\hline Site variable & Description \\
\hline Diameter $(\mathrm{cm})$ & Tree diameter at $10 \mathrm{~cm}$ above ground \\
Nearest tree $(\mathrm{cm})$ & Distance to nearest tree \\
Shrubs $(\%)$ & Foliage volume of shrubs between \\
& 0 and $1.5 \mathrm{~m}$ height (visual estimate) \\
\hline
\end{tabular}

where main effect was significant were made using least significant difference (LSD) tests at 0.05 level of probability (Snedecor and Cochran, 1980).

For comparing characteristics of available (larger scale) with rubbed trees, we considered as fixed factors in REML species identity at four levels (B. alba, Pinus pinaster, P. menziensii, $Q$. robur) and rubbing at three levels (available tree, tree rubbed by red deer and tree rubbed by roe deer). For comparing characteristics of rubbed with nearest unrubbed trees we made separate REML analyses for red and roe deer considering as fixed factors tree species at four levels (as above) and rubbing at two levels (tree rubbed, nearest unrubbed tree). Additionally each pair of rubbed and its nearest unrubbed tree was blocked and considered as a random factor in REML, to allow comparison of tree characteristics whilst controlling for local environmental factors. REML analyses described above were also conducted for each tree species separately. Proportions of shrub cover were angular transformed to meet assumptions of normality (Zar, 1996).

\section{Results}

\subsection{Temporal and spatial variation of rubbing}

We found 94 trees rubbed by red and 42 trees rubbed by roe deer (Table 2) with selection of tree species for rubbing differing between deer species (G-deer species $\times$ tree species $=20.6$, d.f. $=3, P<0.001)$. The distribution of rubs off different deer species across different tree species demonstrates that red and roe deer vary in their rubbing behaviour at larger scales. Subsequent sections investigate the finer scale processes underling this difference. Red deer rubbed trees mainly between September and February and roe deer mainly between December and June (G-deer species $\times$ sampling period $=61.5$, d.f. $=4, P<0.001$ ) (Fig. 1). Rubbing of trees in relation to the edge of the plantations also differed between deer species (Gdeer species $\times$ distance from edge $=13.1$, d.f. $=3, P<0.01$ ) with red deer showing a preference for rubbing trees along the edge of plantations (Fig. 2).

\subsection{Available and rubbed trees}

Trunk diameter differed significantly among tree species (Wald $=17.8$, d.f. $=3, \quad P=0.001$ ) with a tendency for deciduous trees (B. alba and $Q$. robur) to have larger diameters

Table 2

Number of trees rubbed by red and roe deer in plantations of Pinus pinaster, Pseudotsuga menziensii, Betula alba and Quercus robur and expected frequencies of rubbed trees (in brackets) as estimated from the data for calculating Glikelihood ratio tests

\begin{tabular}{lllllr}
\hline Deer species & \multicolumn{2}{l}{ Plantations } & \multicolumn{3}{c}{ Total } \\
\cline { 2 - 5 } & Pinus pinaster & P. menziensii & B. alba & Q. robur & \\
\hline Red deer & $50(55.3)$ & $22(15.9)$ & $19(15.9)$ & $3(6.9)$ & 94 \\
Roe deer & $30(24.7)$ & $1(7.1)$ & $4(7.1)$ & $7(3.1)$ & 42 \\
Total & 80 & 23 & 23 & 10 & 136 \\
\hline
\end{tabular}




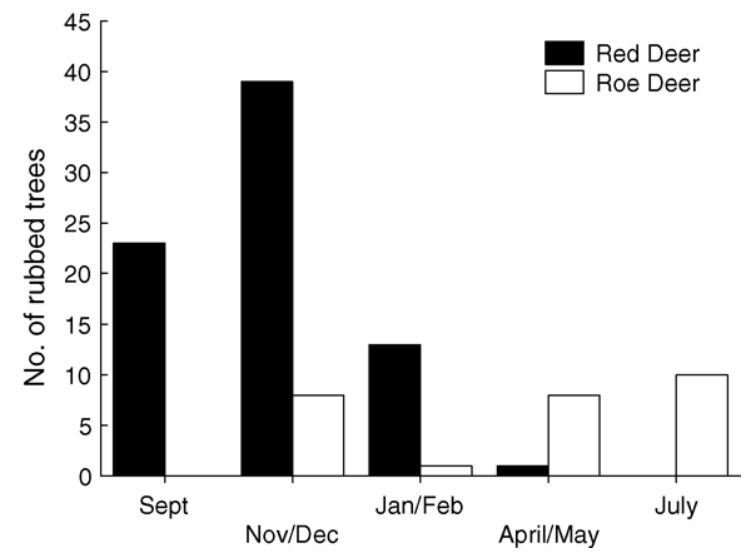

Fig. 1. Seasonal variation in the number of trees recorded as newly rubbed by red and roe deer.

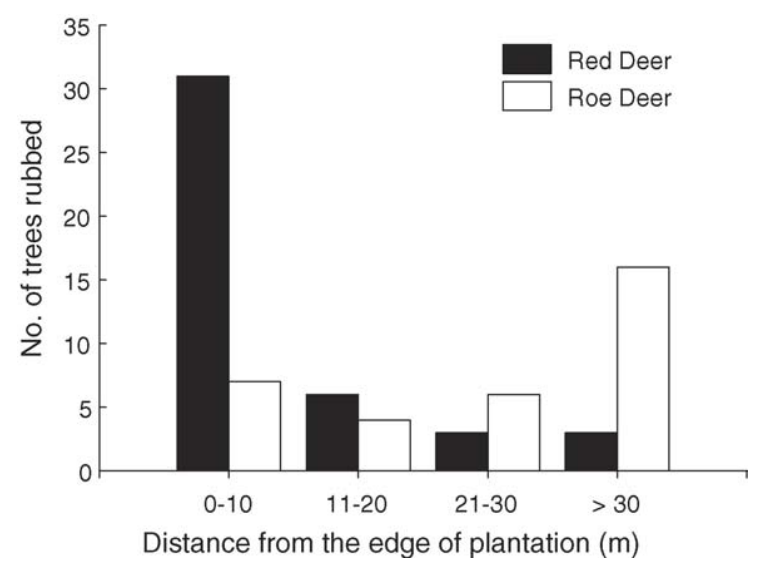

Fig. 2. Number of trees rubbed by red and roe deer in forestry plantations in relation to distance from the edge of plantation. than coniferous trees (Pinus pinaster and P. menziensii) (Table 3). There were also significant differences in distance to nearest tree among tree species (Wald $=50.9$, d.f. $=3$, $P<0.001)$ these being larger in $B$. alba plantations and differing significantly from distances to nearest tree of Pinus pinaster and $Q$. robur plantations. Shrub cover differed significantly among tree species (Wald $=28.1$, d.f. $=3$, $P<0.001)$ and was highest in Pinus pinaster, differing significantly from shrub cover of $P$. menziensii and $Q$. robur but not from $B$. alba plantations. A significant interaction between trees species and rubbing by red or roe deer was found for trunk diameter (Wald $=24.7$, d.f. $=6, P<0.001$ ) and approached significance for shrub cover (Wald $=10.8$, d.f. $=6$, $P=0.094$ ) but was not significant for distance to nearest tree (Wald $=4.4$, d.f. $=6, P=0.613$ ).

Overall, there were significant differences between the average diameters of available and rubbed trees (Wald $=83.1$, d.f. $=2, P<0.001)$ with available trees being significantly larger than trees rubbed either by red deer or roe deer (Table 3). This also occurred in Pinus pinaster and $Q$. robur plantations, with diameter of available trees differing significantly from diameter of trees rubbed by red and roe deer, and approached significance in $B$. alba plantations (Table 3). Diameter of trees rubbed by roe deer was also significantly smaller than diameter of trees rubbed by red deer (Tables 3 and 4) with significant differences being detected overall and in Pinus pinaster, B. alba and Q. robur plantations (Table 3). Shrub cover differed significantly between available and rubbed trees (Wald $=14.1$, d.f. $=2$, $P<0.001$ ). There was a tendency for available trees to have higher shrub cover than rubbed trees, however significant differences were only detected in Pinus pinaster plantations for both red and roe deer and overall for roe deer (Table 3). Pinus pinaster trees rubbed by red deer also

Table 3

Comparison of characteristics of trees "available", "rubbed by red deer" and "rubbed by roe deer" in plantations of Pinus pinaster, Pseudotsuga menziensii, B. alba and Q. robur. S.E.D. is the standard error of difference for comparisons within rows. Comparisons between "available", "rubbed by red" and "rubbed by roe" deer were made within tree species using the least significance difference test. Unlike letters represent significant differences within rows. Sample sizes of trees "available", "rubbed by red" and "rubbed by roe" deer were, respectively: all species (70, 94, 42), Pinus pinaster (40, 50, 30), Pseudotsuga menziensii (14, 22, 1), B. alba $(12,19,4)$ and $Q . \operatorname{robur}(4,3,7)$

\begin{tabular}{|c|c|c|c|c|c|c|c|c|}
\hline Variate & Tree species & Available & Rubbed red deer & Rubbed roe deer & S.E.D. & Wald & d.f. & $P$ \\
\hline \multirow[t]{5}{*}{ Diameter $(\mathrm{cm})$} & All species & $17.1 \mathrm{a}$ & $9.9 \mathrm{~b}$ & $4.4 \mathrm{c}$ & 1.8 & 83.1 & 2 & $<0.001$ \\
\hline & Pinus pinaster & $13.4 \mathrm{a}$ & $7.6 \mathrm{~b}$ & $3.2 \mathrm{c}$ & 1.34 & 69.2 & 2 & $<0.001$ \\
\hline & Pseudotsuga menziensii & 10.7 & 9.9 & 4.3 & 4.69 & 2.0 & 2 & 0.370 \\
\hline & B. alba & 17.1 & 15.5 & 7.0 & 2.93 & 4.6 & 2 & 0.098 \\
\hline & Q. robur & $27.1 \mathrm{a}$ & $6.7 \mathrm{~b}$ & $3.1 \mathrm{~b}$ & 4.05 & 21.6 & 2 & $<0.001$ \\
\hline \multirow[t]{5}{*}{ Nearest tree $(\mathrm{cm})$} & All species & 173.5 & 178.8 & 144.0 & 26.89 & 3.4 & 2 & 0.181 \\
\hline & Pinus pinaster & 153.1 & 137.3 & 125.4 & 20.03 & 1.9 & 2 & 0.394 \\
\hline & Pseudotsuga menziensii & 182.9 & 214.1 & 230.0 & 70.30 & 1.7 & 2 & 0.437 \\
\hline & B. alba & 242.9 & 250.3 & 157.5 & 43.80 & 2.2 & 2 & 0.342 \\
\hline & Q. robur & 115.0 & 113.7 & 63.3 & 60.93 & 4.9 & 2 & 0.087 \\
\hline \multirow{5}{*}{$\begin{array}{l}\text { Shrub cover }(\%) \\
\quad \text { (angular transformed) }\end{array}$} & All species & $0.3874 \mathrm{a}$ & $0.4025 \mathrm{a}$ & $0.172 \mathrm{~b}$ & 0.0920 & 14.1 & 2 & $<0.001$ \\
\hline & Pinus pinaster & $0.6337 \mathrm{a}$ & $0.4776 \mathrm{~b}$ & $0.3333 \mathrm{c}$ & 0.0682 & 16.0 & 2 & $<0.001$ \\
\hline & Pseudotsuga menziensii & 0.4128 & 0.5239 & 0.0000 & 0.2391 & 4.2 & 2 & 0.125 \\
\hline & B. alba & 0.4749 & 0.5751 & 0.2736 & 0.1491 & 3.2 & 2 & 0.197 \\
\hline & Q. robur & 0.0250 & 0.0334 & 0.0811 & 0.2074 & 1.8 & 2 & 0.404 \\
\hline
\end{tabular}


Table 4

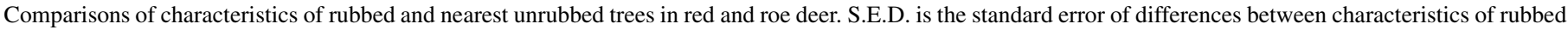
and nearest unrubbed trees

\begin{tabular}{|c|c|c|c|c|c|c|c|c|c|c|c|c|c|}
\hline Variate & Tree species & $\begin{array}{l}\text { Red deer } \\
\text { rubbed }\end{array}$ & $\begin{array}{l}\text { Nearest } \\
\text { unrubbed }\end{array}$ & S.E.D. & Wald & d.f. & $P$ & $\begin{array}{l}\text { Roe deer } \\
\text { rubbed }\end{array}$ & $\begin{array}{l}\text { Nearest } \\
\text { unrubbed }\end{array}$ & S.E.D. & Wald & d.f. & $P$ \\
\hline \multirow[t]{5}{*}{ Diameter $(\mathrm{cm})$} & All species & 9.7 & 13.2 & 0.9 & 15.4 & 1 & $<0.001$ & 4.4 & 13.0 & 2.7 & 31.8 & 1 & $<0.001$ \\
\hline & Pinus pinaster & 7.6 & 11.7 & 1.0 & 15.4 & 1 & $<0.001$ & 3.2 & 8.8 & 1.4 & 15.2 & 1 & $<0.001$ \\
\hline & P. menziensii & 9.9 & 14.5 & 1.6 & 8.1 & 1 & 0.004 & 4.3 & 10.0 & n.d. & & & \\
\hline & B. alba & 15.5 & 16.6 & 2.8 & 0.2 & 1 & 0.700 & 7.0 & 9.7 & 2.3 & 1.4 & 1 & 0.238 \\
\hline & Q. robur & 6.7 & 9.2 & 4.0 & 0.4 & 1 & 0.534 & 3.1 & 21 & 5.2 & 15.0 & 1 & $<0.001$ \\
\hline \multirow[t]{5}{*}{ Nearest tree $(\mathrm{cm})$} & All species & 177.4 & 146.6 & 8.6 & 12.8 & 1 & $<0.001$ & 144.0 & 120.1 & 18.4 & 10.3 & 1 & $<0.001$ \\
\hline & Pinus pinaster & 137.3 & 106.6 & 9.9 & 9.6 & 1 & 0.002 & 125.4 & 89.6 & 12.4 & 8.3 & 1 & 0.004 \\
\hline & P. menziensii & 214.1 & 189.5 & 18.8 & 1.7 & 1 & 0.192 & 230.0 & 220.0 & n.d. & & & \\
\hline & B. alba & 250.3 & 214.2 & 25.6 & 2.0 & 1 & 0.159 & 157.5 & 107.5 & 29.2 & 2.9 & 1 & 0.086 \\
\hline & Q. robur & 113.7 & 70.0 & 14.5 & 9.1 & 1 & 0.003 & 63.3 & 63.3 & 0.2 & 0.0 & 1 & 1.000 \\
\hline \multirow{5}{*}{$\begin{array}{l}\text { Shrub cover }(\%) \\
\quad \text { (angular transformed) }\end{array}$} & All species & 0.494 & 0.493 & 0.037 & 0.0 & 1 & 0.994 & 0.172 & 0.274 & 0.070 & 17.7 & 1 & 0.001 \\
\hline & Pinus pinaster & 0.478 & 0.523 & 0.042 & 1.2 & 1 & 0.0481 & 0.333 & 0.511 & 0.048 & 13.9 & 1 & $<0.001$ \\
\hline & P. menziensii & 0.524 & 0.419 & 0.078 & 1.8 & 1 & 0.176 & 0.000 & 0.000 & n.d. & & & \\
\hline & B. alba & 0.551 & 0.575 & 0.112 & $0 . .1$ & 1 & 0.831 & 0.274 & 0.462 & 0.076 & 6.1 & 1 & 0.014 \\
\hline & Q. robur & 0.033 & 0.199 & 0.066 & 6.4 & 1 & 0.012 & 0.0 .81 & 0.124 & 0.032 & 1.8 & 1 & 0.184 \\
\hline
\end{tabular}

had significantly higher shrub cover than trees rubbed by roe deer (Table 3). Distance to nearest tree did not differ significantly between available and rubbed trees.

\subsection{Rubbed and nearest unrubbed trees}

Rubbed trees had smaller diameters than unrubbed trees both in red (Wald $=15.4$, d.f. $=1, P<0.001$ ) and roe deer (Wald $=31.8$, d.f. $=1, P<0.001) \quad($ Table 4$)$. There was a significant interaction between tree species and rubbing in roe (Wald $=17.2$, d.f. $=3, \quad P<0.001$ ) but not in red deer (Wald $=2.4$, d.f. $=3, P=0.494$ ). Significant differences on average trunk diameter between rubbed and nearest unrubbed trees were also detected for red deer in Pinus pinaster and $P$. menziensii plantations, and for roe deer in Pinus pinaster and $Q$. robur plantations (Table 4). Distance between rubbed and nearest unrubbed tree differed significantly both in red (Wald $=12.8$, d.f. $=1, P<0.001$ ) and roe deer (Wald $=10.3$, d.f. $=1$, $P<0.001$ ) (Table 4). Significant differences on distance between rubbed and nearest unrubbed trees were also detected for red deer in Pinus pinaster and Q. robur plantations and for roe deer in Pinus pinaster and approaching significance in $B$. alba plantations (Table 4). Overall, shrub cover differed significantly between rubbed and nearest unrubbed trees, being lower in rubbed trees, in roe (Wald $=17.7$, d.f. $=1, P<0.001$ ) but not red deer (Table 4$)$. In the case of roe deer, significant differences were detected in Pinus pinaster and B. alba plantations whilst for red deer a significant difference was detected in $Q$. robur plantations, with rubbed trees having higher shrub cover than nearest unrubbed trees, but not in other tree species (Table 4).

\section{Discussion}

\subsection{Temporal variation of tree rubbing}

There was a clear temporal segregation in the number of trees rubbed by red and roe deer. Whilst the number of trees rubbed by red deer peaked in November-December the number of trees rubbed by roe was more evenly distributed from November to July. This reflects the biological cycle and the mating season of each species. In the case of red deer, the maximum number of trees that was rubbed coincided with the peak of the mating season of red deer in the area (OctoberNovember). Red deer is a non-territorial species but males defend harems of females only during the rut (Clutton-Brock et al., 1982). The rut is a period of high interaction among males. If red deer rubs are associated with visual or olfactory signals during the rut then rubbing intensity should coincide with this period. We found no studies on rubbing behaviour for red deer, however, Bowyer and Kitchen (1987) showed that in the case of Roosevelt Elk (C. elaphus roosevelti) rubbing was associated with scent marking and coincided with the period of maximum agonistic interactions among males, during the rut.

In the case of roe deer our results show that the number of trees that were rubbed tended to increase from January to February until July. Roe deer is a highly territorial species with a high degree of site fidelity during summer (Johansson, 2000; Linnell and Andersen, 1998). In roe deer, rubbing antlers against trees is often associated with scent marking of territories (Linnell and Andersen, 1998). Territorial marking usually starts in early spring (March-April) and continues until the end of the rut in summer (end of August) (Geist, 1998; Linnell and Andersen, 1998; Johansson, 2000) which partly agrees with our results. The relatively high number of trees found rubbed by roe deer in early winter (NovemberDecember) is surprising and more difficult to explain. Roe deer usually cast their antlers between October and November and antler re-growth starts immediately after casting (Sempéré et al., 1998). Thus by November-December roe deer antlers should still be in full velvet. Johansson (1996) found that, in Sweden, roe deer male territorial behaviour starts in early March and that all territories are established 1-3 weeks before all males shed velvet, concluding that to be in hard antlers is not a requirement for territory take up. At lower latitudes biological 
cycles, including deer reproductive cycles, tend to start earlier (Bronson, 1989). Although there are no studies on roe deer antler cycle at Portuguese latitudes it is possible that by November-December roe deer are starting to rub trees which may play a role in the maintenance of roe deer winter territories.

\subsection{Spatial variation of tree rubbing}

Red deer rubbed trees preferentially along the edge of plantations (although large clearings inside plantations were also selected, pers. observ.) whilst roe deer showed a tendency for rubbing trees within plantations. The red deer is a gregarious, non-territorial species for most of the year that needs relatively open spaces and probably relies more heavily on visual communication than roe deer (Geist, 1998). Tree rubs along the edge of plantations or large clearings are highly visible and presumably more effective as visual communication than rubs within dense vegetation (Massei and Bowyer, 1999). The roe deer, on the contrary, is a highly territorial, solitary or small group species, with a preference for relatively closed spaces (Geist, 1998; Liberg et al., 1998). Our results on spatial variation of rubbing may thus reflect differential habitat preferences of each species.

Although not measured in our study, natural tree regeneration, and thus availability of saplings, was low in $P$. menziensii and $B$. alba plantations (pers. observ.). Saplings and smaller diameter trees are preferentially selected by roe deer for rubbing (see below), which may have contributed to the very low number of trees rubbed by roe deer, as compared to red deer, in $P$. menziensii and B. alba plantations.

\subsection{Characteristics of available rubbed and nearest unrubbed trees}

Trees rubbed by red and roe deer were significantly smaller than trees available indicating selection for tree size (trunk diameter) in both deer species. Diameter of trees selected is probably related to species body size and possibly to size and morphology of antlers. It should be more effective for red deer to place and rub antlers against medium sized trees whilst for roe deer smaller trees and saplings are more likely to fit between their antlers. Trees rubbed by roe but not by red deer had lower shrub cover protection than trees available indicating selection for lower shrub cover in roe as compared to red deer. This suggests that roe deer select areas relatively clear from shrubs within plantations as the number of trees rubbed by roe deer also tended to increase with distance from edge of plantations (see above).

Both red and roe deer selected trees which had smaller diameters than nearest unrubbed trees indicating local selection for tree size. Trees rubbed by roe deer however tended to be more closely spaced than those rubbed by red deer. Body size relates to home range size (Peters, 1983) and possibly perception of the environment (Kiltie, 2000; Fernandez-Juricic et al., 2004). Red deer have larger home ranges and thus more extensive areas for rubbing antlers than roe deer. The roe deer, by contrast, is a highly territorial species with smaller home ranges. As a result it may rub less extensive areas and favour trees which are closer together than those preferred by red deer.

Physical accessibility to trees affected rubbing by each deer species differently. This is a result that may also be related to body size. Red deer, with a larger body size and antler length than roe, is probably able to rub trees even if they are surrounded by shrubs.

\subsection{Mitigation and implications for management}

Rubbing may ultimately cause death of trees. For instance, Bowyer et al. (1994) showed that the tops of $18.5 \%$ of 54 trees rubbed by moose were dead as compared to only $0.5 \%$ of 201 trees that were available for rubbing. Although not assessed in our study mortality induced by rubbing is likely to vary differentially with deer and tree species (conifer or hardwood) as well as season of rubbing. For instance, tree wounds induced by red deer rubs are usually larger and deeper than those caused by roe deer. Although size of wound needs to be considered in relation to tree size (and trees rubbed by roe deer are smaller than those rubbed by red deer) red deer rubs are probably more likely to damage the tree cambium and cause severe injury to trees than roe deer rubs.

Our results suggest that tree damage due to rubbing by red deer is more likely to occur along edges of plantations and clearings. Inside plantations, small trees (for instance those that are replanted or natural regenerated) are more likely to be damaged by roe deer and should be probably protected from this deer species in particular. The results also indicate that shrubs around trees may be an effective protection against roe but not red deer. Leaving a shrub understorey in forest plantations for minimising deer damage to trees is a potential mitigation measure that must be balanced against the increased risk of fire and possible competition between shrubs and trees. Deer control or tree protection are other possible ways of reducing rubbing damage, however this must also be considered in relation to revenues provided by deer hunting, which may compensate possible economic losses due to tree mortality or wood damage caused by deer rubbing.

Tree rubbing is probably affected not only by the density of deer populations but also by male:female ratios. In the case of territorial species such as roe deer, overall population density may affect the size and the number of established territories and consequently the number and characteristics of rubbed trees (Johansson, 2000). In species, such as red deer, that defend harems of females during the rut, male:female ratios, may affect mating behaviour and thus the number and location of rutting areas and trees within these areas. These factors require further investigation.

\section{Acknowledgements}

This study was funded by the Portuguese Science Foundation (FCT), project POCTI/1999/AGR/33929 "The feeding ecology of deer effects on the natural regeneration of trees". We thank José Luís Rosa of Parque Natural de Montesinho for suggestions, students of Escola Superior 
Agrária of Bragança for help in fieldwork and Mark Brewer of BIOSS for statistical advice and two anonymous referees for their comments. M.N. Bugalho was funded by the FCT postdoctoral grant SFRH/727/2000.

\section{References}

Benner, J.M., Bowyer, R.T., 1988. Selection of trees for rubs by white-tailed deer in Maine. J. Mammal. 69, 624-627.

Bowyer, R.T., Ballenberghe, V., Rock, K.R., 1994. Scent marking by Alaskan moose: characteristics and spatial distribution of rubbed trees. Can. J. Zool. 72, 2186-2192.

Bowyer, R.T., Kitchen, D.W., 1987. Significance of scent marking by Roosevelt Elk. J. Mammal. 68, 418-423.

Bronson, F.H., 1989. Mammalian Reproductive Biology. University of Chicago Press, Chicago.

Carranza, J., Mateos-Queseda, P., 2001. Habitat modification when scent marking: shrub clearance by roe deer bucks. Oecologia 126, 231-238.

Clutton-Brock, T.H., Guiness, F.E., Albon, S.D., 1982. Red Deer: Behaviour and Ecology of Two Sexes. University of Chicago Press, Chicago.

Fernandez-Juricic, E., Erichsen, J.T., Kacelnik, A., 2004. Visual perception and social foraging in birds. Trends Ecol. Evol. 19, 25-31.

Fuller, R.J., Gill, R.M.A., 2001. Ecological impacts of increasing numbers of deer in British woodland. Forestry 74, 193-199.

Geist, V., 1998. Deer of the World. Mechanicsburg Press, Mechanicsburg.

Genstat 6th for Windows, 2002. Lawes Agricultural Trust. Rothamsted Experimental Station.

Gill, R.M.A., 1992. A review of damage by mammals in North Temperate Forests. 1. Deer. Forestry 65, 145-169.

Gill, R.M.A., Beardall, V., 2001. The impact of deer on woodlands: the effects of browsing and seed dispersal on vegetation structure and composition. Forestry $74,209-218$

Harmer, R., 2002. The effect of plant competition and simulated summer browsing by deer on tree regeneration. J. Appl. Ecol. 38, 1094 1103.

Johansson, A., 1996. Territory establishment and antler cycle in male roe deer Ethology 102, 549-559.

Johansson, A., 2000. Effect of roe removal on marking intensity. Acta Theriol. $45,123-128$.

Johansson, A., Liberg, O., 2000. Functional aspects of marking behaviour by male roe deer (Capreolus capreolus). J. Mammal. 77, 558-567.

Johansson, A., Liberg, O., Wahlstrom, L.K., 1995. Temporal and physical characteristics of scaping and rubbing in roe deer (Capreolus capreolus). $\mathrm{J}$. Mammal. 76, 123-129.
Kile, T.L., Marchinton, R.L., 1977. White-tailed deer rubs and scrapes: spatial, temporal and physical characteristics and social role. Am. Midl. Nat. 97, 257-266.

Kiltie, R.A., 2000. Scaling of visual activity acuity with body size in mammals and birds. Funct. Ecol. 14, 226-234.

Kirby, K.J., 2001. The impact of deer on the ground flora of British broadleaved woodland. Forestry 74, 219-229.

Liberg, O., Johansson, A., Andersen, R., Linnell, J.D.C., 1998. Mating system, mating tactics and the function of male territoriality in roe deer. In: Anderson, R., Duncan, P., Linnel, J.D.C. (Eds.), The European Roe Deer: The Biology of Success. Scandinavian University Press, Oslo.

Linnell, J.D.C., Andersen, R., 1998. Territorial fidelity and tenure in roe deer bucks. Acta Theriol. 43, 67-75.

Massei, G., Bowyer, R.T., 1999. Scent marking in fallow deer: effects of lekking behaviour on rubbing and wallowing. J. Mammal. 80, 633-638.

Miller, K.V., Kammermeyer, K.E., Marchinton, R.L., Moser, E.B., 1987. Population and habitat influences on antler rubbing by white-tailed deer. J. Wildl. Manage. 51, 62-66.

Nielsen, D.G., Dunlap, M.J., Miller, K.V., 1982. Pre-rut rubbing by white-tailed bucks: nursery damage, social role, and management options. Wildl. Soc. Bull. 10, 341-348

Oeheler, M.W., Jenks, J.A., Bowyer, R.T., 1995. Antler rubs by white-tailed deer: the importance of trees in a prairie environment. Can. J. Zool. 73, 1383-1386.

Paiva, J., 2004. Estimating Red and Roe Deer Population Densities in Parque Natural de Montesinho. First Degree Thesis. University of Coimbra, Coimbra (in Portuguese).

Peters, R.H., 1983. The Ecological Implications of Body Size. Cambridge University Press, Cambridge.

Putman, R.J., Moore, N.P., 1998. Impact of deer in lowland Britain on agriculture, forestry and conservation habitats. Mammal. Rev. 28, 141-164.

Ralls, K., 1971. Mammalian scent marking. Science 171, 443-449.

Rooney, T.P., 2001. Deer impact on ecosystems: a North American perspective. Forestry 74, 201-208.

Sempéré, A.J., Mauget, R., Mauget, C., 1998. Reproductive physiology of roe deer. In: Andersen, R., Duncan, P., Linnell, J.D.C. (Eds.), The European Roe Deer: The Biology of Success. Scandinavian University Press, Oslo.

Snedecor, G.W., Cochran, W.G., 1980. Statistical Methods. Iowa State University Press, Ames, Iowa.

Sokal, R.R., Rohlf, F.J., 1995. Biometry: The Principles and Practice of Statistics in Biological Research. W.H. Freeman \& Company, New York.

Virtanen, R., Edwards, G.R., Crawley, M.J., 2002. Red deer management and vegetation on the Isle of Rum. J. Appl. Ecol. 39, 572-583.

Zar, J.H., 1996. Biostatistical Analysis, 3rd ed. Prentice Hall International, Inc., Upper Saddle River, N.J. 